\title{
Creating wisdom cultures Integral Coaching as applied foresight in leadership development
}

$\mathrm{S}$

ystemic or integral frameworks are needed not only in our projects of creating knowledge and understanding, but also in our attempts to change the world, to make better futures. Transcending the flatland of one-dimensional materiality is pivotal in business, politics and everyday life. Therefore it is understandable that Ken Wilber's Integral Theory has inspired not only those who wish to cultivate understanding, but also those who have the agenda of creating better futures for human organizations, societies or workplaces. In this article we will first look at the contribution of the futurist Richard Slaughter, who has utilized Wilber's insights on spirituality in his foresight concepts and practice. Secondly we will focus on leadership development, utilizing Slaughter's notion of wisdom culture. Thirdly we will present Wilberian integral coaching as a tool for creating wisdom cultures in business. Finally we will discuss how spirituality and wisdom culture are founded on our ontological concepts of human development and reality.

\section{Introduction: wisdom culture}

One of the core meanings of spirituality is that it involves mental contents that conceptualize the world in terms of interconnected, networked entities, where the one-dimensional materiality of the flatland is transcended. It could be argued that spirituality is a branch of systems thinking, spiced with compassion, love and empathy. Carefully implemented spirituality involving systems thinking and compassion provide means for generating better futures. Spiritual mental contents are therefore relevant in business coaching as well as in general futures research and foresight activities.
A futurist and expert in applied foresight, Richard A. Slaughter has become one of the central figures in applying Wilber's Integral Theory to future studies, foresight practices and business coaching. In his book To See With Fresh Eyes: Integral Futures and the Global Emergency (2012) Slaughter introduces the notion of 'wisdom culture' towards which futurists and business coaches should strive. Wisdom culture is pervaded by spirituality, implicating that its bearers should see the world as a systemic whole, where the flatland of one-dimensional materiality is transcended. Wisdom culture emerges from current formations even though its manifestations, qualitatively novel as they are, have not been easy to recognize, as Slaughter writes:

\begin{abstract}
The kind of cultural editing that has occurred within Western cultures has either ignored or misrepresented the higher levels of a qualitatively differentiated world. It has made them appear mysterious or esoteric, the realm of gurus, mystics or charlatans. In fact they are simply part of a wider pattern. Just as a clock is more than the sum of its parts and a living organ is more than the sum of its cells, so the more highly evolved manifestations of human consciousness reach transcendent levels.
\end{abstract}

(Slaughter 2012: 39-40)

Slaughter follows Wilber in arguing that rationality is not the endpoint of mental and cultural evolution, but rather a stage that should be transcended and included (Slaughter 2012: 63). Spirituality and the wisdom culture that builds upon it is first and foremost an epistemological recovery, a novel way of seeing things. Depth and meaning in our relation- 


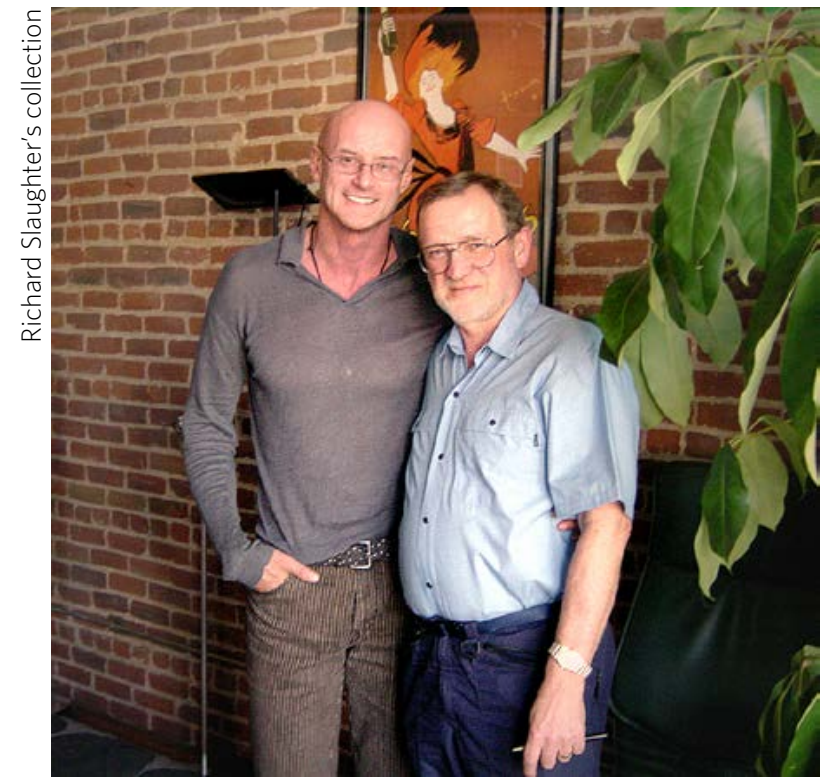

Ken Wilber (left) and Richard Slaughter in Boulder, Colorado in 2003.

ship to the world is only marginally dependent on technology, but largely dependent on the 'progressive refinement of the instrument of knowing itself - that is, through the capabilities and perceptions of each individual person .... and the corresponding new stages of civilized life' (Slaughter 2012: 69).

Like Wilber, Slaughter does not undervalue technological and scientific progress, but rather he challenges human beings to accelerate human and social evolution so that it matches science and technology.

Following Wilber and Slaughter, spirituality can be seen as a framework that facilitates voluntary and conscious growth in order to feel at home in the Kosmos, which includes the diversity of emergent entities transcending the flatland of one-dimensional materiality. In that regard by creating wisdom cultures in business through leadership development we invoke spirituality in business. It could be argued that every authentic developmental transition (transformation) in an organization and its personnel, including most importantly the leader(s), can be seen as practical spirituality in the place where we most likely spend the majority of our waking hours: our work, our business and our organizations. Transcending the flatland becomes, then, an everyday task and an everyday activity. In the future world of business practical spirituality in the form of situating the organization within the largest whole possible - and acting accordingly - can be as important as following the bottom line is now.
We will argue that the primary responsibility of a business leader is to create an integral wisdom culture in his or her business environment. Using the concepts of wisdom culture and applied foresight from Slaughter, we establish our argument in three parts, with one addendum:

1. Leadership can and should encourage the creation of wisdom cultures.

2. The creation of wisdom culture dovetails with the understanding of how an unwise business culture is constructed by explicating three major 'self-constructed traps' (Slaughter 2003: 95).

3. Creating a wisdom culture is dependent on the emergence of a New Way of Being in the leader by transcending and including their Current Way of Being into a larger, more systemic way of seeing, thinking and doing.

Addendum: Leadership development can be fostered by means of coaching. In this article we will look into an integral application of coaching called, appropriately, Integral Coaching ${ }^{\circledR}$.

In what follows we focus mainly on leadership in the arena of business organizations. Leadership could be, however, seen as leadership in universities, churches or any other arena where people are congregated to further a common goal, or a set of goals. Following this thread, applied foresight applied to creating wisdom cultures with the means of emergent New Ways of Being could be seen as the primary responsibility of a leader, period. There is no need to separate the arenas where leadership itself is applied. For the purposes of this article, though, we will focus on the leadership in business.

\section{Leadership as creating wisdom cultures}

Richard Slaughter suggests that a viable future for humankind cannot be based on industrial era assumptions, models and values. In his work on futures beyond dystopia, Slaughter proposes the notion of wisdom culture as a concept for bringing a 'future worth living in' within intellectual and practical reach:

Such a [wisdom] culture is far-sighted and imbued throughout with trans-personal awareness. A sense of this future is presently missing 
from our everyday awareness... The route from here (the slide toward destruction) to there (a future worth living in) is through the growth of human awareness across the planet and the implementation of future-saving, futurecreating, structures and processes. Most of these already exist but they remain culturally marginalized. A key to their mainstream emergence is an advanced futures discourse that can critique and re-shape existing agendas. ... [T] he goal is to work toward the creation of social foresight and the steady emergence of societies and cultures that are not merely past-driven, but responsive to the emerging near-term future context. (Slaughter 2003: 30)

Several points here should be made.

First, as we approach the topic of leadership we adopt a decidedly individual angle. The quote from Slaughter translates, then, into the realm of business leadership as follows:

i. Growth of human awareness and the futuresaving and future-creating structures and processes are not only culturally, but also psychologically marginalized.

ii. The key to their emergence in the leader is an advanced futures discourse concentrating on the future vs. current Way of Being of the leader himself, the purpose of which is to critique (to see the limitations) and re-shape existing agendas (to see the benefits, and also to see the needed emergent abilities).

iii. This discourse is specifically conducted by a series of coaching conversations, here reflected through a framework of the Integral Coaching method and process.

Creating social foresight by developing wisdom cultures that are not merely past-driven - that is to say, trying to apply yesterday's solutions to the problems and challenges of tomorrow - but responsive to the emerging near-term future context is the main responsibility of the twenty-first century leader. The key word here is responsive. By understanding how the term is used by, for example, Fred Kofman (2006: $31-2)$ response-ability is the ability to respond to a situation. As C. Otto Scharmer (2009: 29) says, we can approach [change] situations from five progressively deeper levels, only the first of which is re-acting. By being responsive - to see, indeed, with fresh eyes - to the emerging near-future context, the leader needs to see the future-saving and future-creating structures that are marginalized in him. Furthermore, we propose that these structures are more often than not 'emergently marginalized', meaning they emerge only when the Current Ways of Being are seen through, and New Ways of Being are envisioned, practised and embodied. They are thus marginalized not as parts of the current psychological makeup of the business professional; but as parts of the emergent capabilities that can come into being by a transcend-and-include developmental process, the central theme of which is realizing the limitations of the current unwise culture the leader has been shaping both in her external (business environment) and internal (individual psychological) organization.

So what are the 'self-constructed traps' into which our organizations keep falling, thus keeping us at the level from where emergent problems are difficult, nay, impossible, to solve? Let us look at those limitations next.

\section{Understanding an unwise business culture}

Business, as life, can be approached from many perspectives. The guiding principle of Wilber's integral AQAL approach is to take into account as many of those perspectives as possible. The overall claim modus operandi, raison dêtre, The Big Why - of the integral framework is, then, that in the twenty-first century nothing less will do. In understanding any given subject, we should at least take into account the many variables that influence and are influenced by that phenomenon (Wilber 2001: 27). Neglecting them constitutes the two major pitfalls of an unwise business culture. We call them 1) Perspectival Partiality and 2) Level Negligence.

\section{Perspectival Partiality}

The Quadrants are the four basic perspectives from which any situation can be assessed (Wilber 2000a: $61-7)$.

We can assess and analyse any situation in business, life and whatever we try to understand, study and develop from individual, collective, interior and exterior dimensions. Usually, as parts of our 'native perspectives' (our natural tendency to orient from one or two of the quadrants) we tend to orient from and identify with one or two of these perspectives more strongly (Divine 2009a). This is natural; 


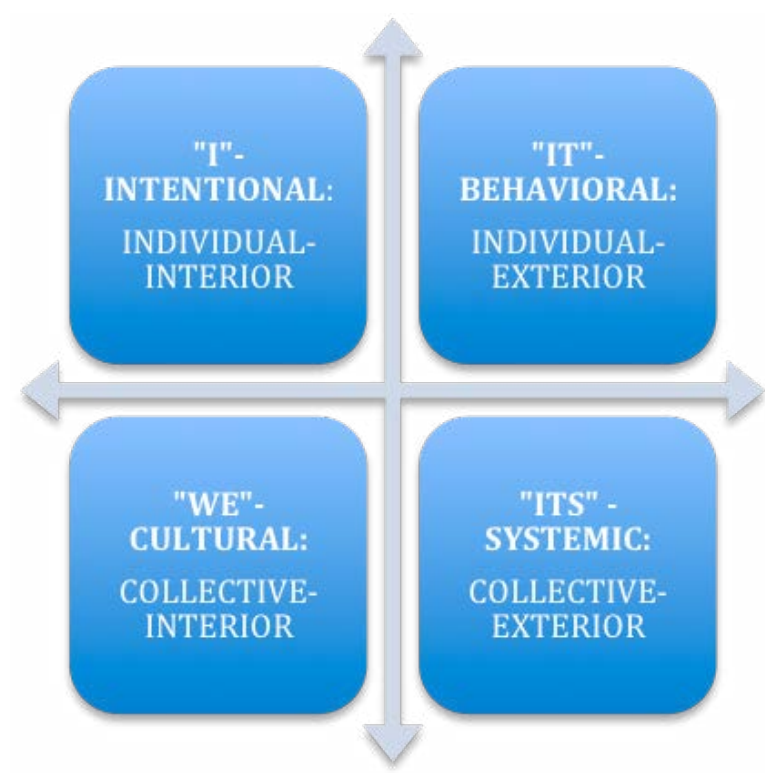

Fig. 1. Four perspectives for analysing any situation (e.g. business).

however, it causes us to be partial in our perspectivetaking abilities, thus influencing strongly the results we get and how we measure them. Someone well versed in exterior dimensions tends to operate from a systemic-holistic or results-numbers point of view, thus leaving both interior perspectives below their radar.

This first pitfall of an unwise business culture we call Perspectival Partiality. It appears in the form of orienting strongly from one quadrant while neglecting the other three. According to Wilber:

The pre-quadratic approaches ... imagine one of these dimensions to be prior or fundamental-and the others to come after or out of the allegedly prior dimension-are caught in what we called quadrant absolutism, which takes a favorite dimension and absolutizes it, making it the ground out of which all other dimensions must issue. (Modernism tends to privilege objectivity; postmodernism tends to privilege intersubjectivity; ecology tends to privilege interobjectivity, etc.) (Wilber 2006)

In business terms, this means not seeing or not prioritizing all of the quadrants, but only one or two of them. This is clearer when we lay out the contents of an all-quadrant business perspective.
Emphasizing only interior meaning, or outcomes, or procedures, or collective values tends to make a business culture lean too heavily into one direction. By ignoring or downplaying one or more quadrant, the organization will leave out one of the environments or dimensions in which a product or service must survive (Wilber 200ob: 94). As Slaughter (1998) says, 'the most interesting futures are not those which spring from one or two of the four quadrants, but from all of them.

\section{Level Negligence}

Level Negligence is the second major organizational trap. There are many versions of this. One reflects what Slaughter calls 'Stages in Developing Social Foresight', the other what Frederic Laloux refers to in his work on 'creating organizations inspired by the next stage of human consciousness' (Slaughter 2003: 173; Laloux 2014: 36, 55). Level Negligence is operating at full speed when businesses are run from one level only, failing to understand a future emergent level. The work of Laloux is very helpful in understanding this.

According to Laloux, humanity has experienced four major ways to collaborate in organizational settings thus far. Each is based on a very different worldview. Each organizational model has brought about major breakthroughs, allowing organizations to tackle more complex problems and achieve new results. Figure 3 simplifies this with the organizational mode or level, its key breakthrough and guiding metaphor.

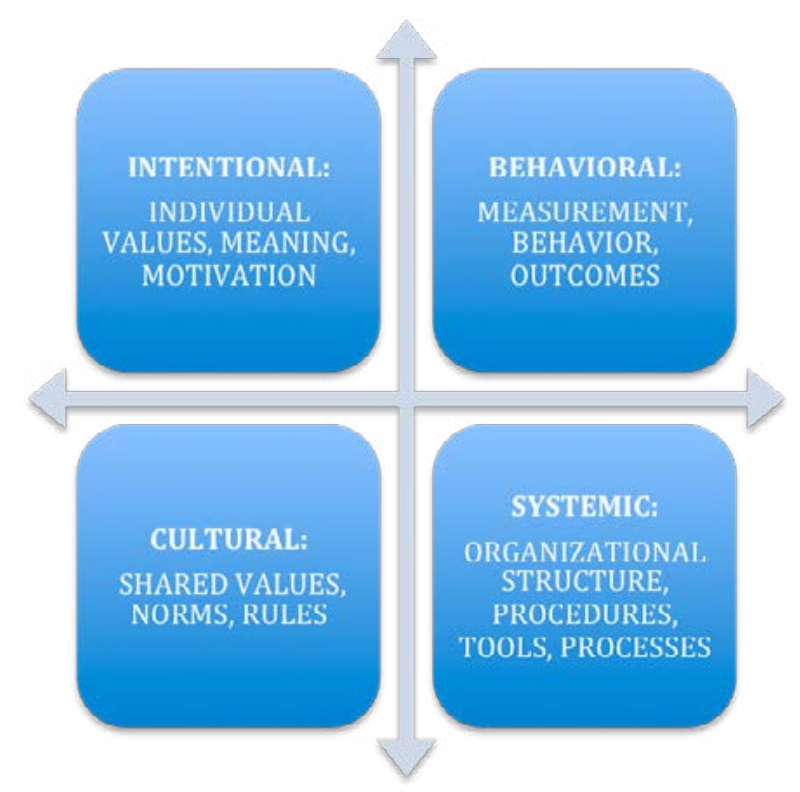

Fig. 2. Four quadrants of an organization. 


\begin{tabular}{|lll|}
\hline Organizational mode & Breakthrough & Metaphor \\
RED organizations & Division of labor & Wolf pack \\
AMBER organizations & Formal roles, processes & Army \\
ORANGE organizations & Innovation, meritocracy & Machine \\
GREEN organizations & Empowerment, values-driven & Family \\
(TEAL organizations) & $?$ & $?$ \\
\hline
\end{tabular}

Fig. 3. Four ways to collaborate in organizations (adapted from Laloux 2014: 36).

It should be noted here that Laloux's use of the colour codes denoting the different levels of organizational mode borrow from Don Beck and Christopher Cowan's seminal work Spiral Dynamics (1996), as well as corresponding to concepts of developmental psychologists like Jane Loevinger, Susan Cook-Greuter, Robert Kegan, William Torbert, Clare Graves, Jean Piaget and Jenny Wade (Laloux 2014: 333).

As the levels give the types of values that will be decisive in both producing and buying the product (Wilber 200ob: 94), the same principle applies here as in Perspectival Partiality. Each level has their particular strengths and weaknesses. We need contributions from each of the levels in managing and leading an organization, since division of labour, processes, innovation and empowerment are all needed. Furthermore, looking at the organization as a social holon, these contributions exist in a systemic environment where different types of values are involved in the buying process and transactions with other parties, stakeholders and the global context. These all should be taken into account. In going beyond Level Negligence by understanding the contributions and limitations of the different levels, Laloux also creates a framework for understanding and implementing the structures, practices and cultures of teallevel organizations, citing examples from the copper industry, grade school, a global energy provider and other arenas of work. An interested reader should consult the original source (Laloux 2014) should they be interested in learning more.

Beyond the integral understanding of the structural pitfalls there is a third, more deeply 'upper- left'; an inside-individual psychological trap that can halt the survival and progress of an organization perhaps even more severely than the two aforementioned constituents of an unwise business culture. For a lack of a better term, we call the third factor Growth Resistance. One can make comparisons to, for example, the work of the Harvard psychologist Robert Kegan (2009) and his studies on immunity to change.

\section{Beyond Growth Resistance: creating wisdom cultures through Integral Coaching}

At the beginning of this article we proposed two things. First, the main responsibility of a business leader is to create a wisdom culture in her organization. Second, this creation is dependent on the emergence of a New Way of Being in the leader herself by transcending and including their Current Way of Being into a larger, more systemic way of seeing, thinking and doing. This is one of the central tenets of Slaughter's view on how futures studies are going forward:

The purpose and goal of this work is precisely to facilitate personal and social evolution beyond the present mental-egoic, capitalist-hegemonic, technical-narcissistic stage to higher stages of personal development and the corresponding new stages of civilised life... while the world's media, and the greater part of the futures literature, continue to be preoccupied with external dangers, external developments, Wilber (and the 
nascent tradition he represents within Future Studies) is pointing across the widely misunderstood divide to the inner world, the other "half" of reality ... In this view, the possibilities for further transformations of human life and culture come from inner work, daily practice, not mere intellectualism stuck within its own heady isolationism. (Slaughter 2004: 124, italics in the original)

For every effort of growth and change in a single practitioner or in an organization there is an opposing force known as resistance or immunity to change (Kegan 2009). At the same time, Josh Floyd, Alex Burns and Jose Ramos (2008) suggest that the development of the practitioner [of future studies] is the primary factor in realizing the benefits of integral futures methodologies. We further that stance by extending it into the realm of business and organizational development, where we maintain that the tools, strategies and 'best practices' are not the primary factors for creating a wisdom culture. The development of the leader is the rigorous backbone upon which the tools and tactics rest and can be operated upon in ways and from levels that were previously out of reach. The same tools used with different evolving and evolved mindsets produce vastly different results.

In what follows we shall focus on explicating what is coaching and how the Integral Coaching method is used in creating wisdom cultures by overcoming the Growth Resistance barrier and fostering healthy leadership development.

\section{Integral Coaching in a nutshell}

Coaching is a human development process that involves structured, focused interaction to promote desirable and sustainable change for the benefit of the coachee and potentially other stakeholders. Nested within this larger field are the various types of coaching, like performance, career, health, wellness and leadership or executive coaching. Executive coaching covers work with executives from middle management upwards, and could be defined as a form of personal learning and development consultation that is provided by a professional outside of the organization who focuses on improving an individual's performance in the executive role (Bachkirova et al. 2010: 1; Stokes and Jolly 2010: 244).

Integral Coaching is a form of coaching based on Ken Wilber's integral model and the adult develop- ment theory of psychologist Robert Kegan. It is used as a coaching framework for people in executive and non-executive roles alike. Canadian Master Certified Coaches Joanne Hunt and Laura Divine founded Integral Coaching as a discipline in 1998. Integral Coaching has been called the most sophisticated professional application of Integral Theory (EsbjörnHargens 2009: v).

Central to the Integral Coaching model is the focus on being a discipline that enables the coaching client:

1. To become more aware of their current approach to situations;

2. To see new possibilities;

3. To build sustainable new competencies to achieve deeply meaningful outcomes.

(Frost 2009: 95-6)

Some clarifications in terminology can be made at this point. First, the current approach to situations is called the Current Way of Being (CWOB) in Integral Coaching. Second, situations can be understood widely, but usually in the coaching process it is taken to mean one particular instance of situations where the client has challenges, for example, certain relationships at work; or situations of work/family balance; or situations of time management issues; or something else altogether. This is called the Coaching Topic. It is also worth noting - and we will expound on this later - that as the client becomes aware of his CWOB in the situation of the coaching topic, it can be seen to appear in many different situations as well. Third, the seeing and building of new possibilities is supported by what is called a New Way of Being (NWOB), first a symbolic but progressively more and more embodied form of different ways of thinking and acting related to the coaching topic.

Developmental, systems-based and rigorously defined coaching methods anchored in research are critical missing components in most coaching schools. They have processes, not methods. There is an apparent lack of coherent parts forming a comprehensive system, built on soundly researched developmental models (Hunt 2009a: 7).

A general overview of the systemic structure of the discipline of Integral Coaching can be simplified like this: 


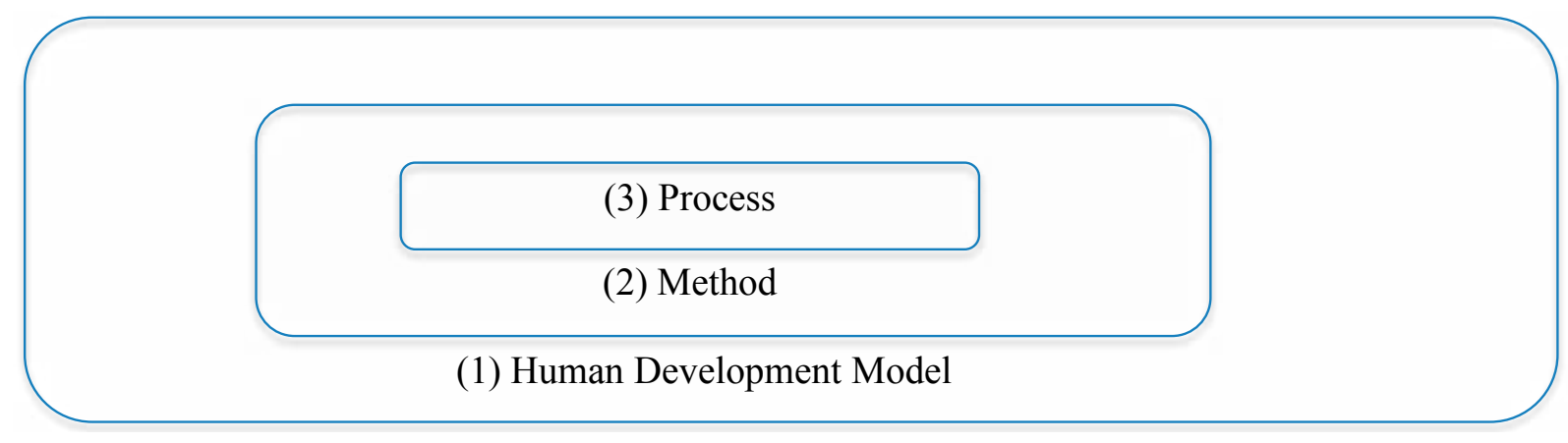

Fig. 4. Integral Coaching Canada's nested system.

The foundational element is the human development model of Robert Kegan's subject-object theory (Kegan 1982). It is a model that reflects the transcendand-include 'mantra' often found in Integral Theory. In short, it is a developmental path where the subject of one level (or a moment in time) becomes the object of a new subject at the next level (or a moment in time). This is how Wilber frames this kind of psychological growth (Wilber 1996: 94):

1. A higher-order structure emerges in consciousness (with the help of symbolic forms);

2. The self identifies its being with that higher structure;

3. The next higher-order structure eventually emerges;

4. The self dis-identifies with the lower structure and shifts its essential identity to the higher structure;

5. Consciousness thereby transcends the lower structure;

6. And becomes capable of operating on that lower structure from the higher-structure level;

7. Such that all preceding levels can then be integrated in consciousness.

Let us see how this process happens in Integral Coaching.

Integral Coaching: method and process

There are four stages in the Integral Coaching method. They manifest in the phases of client development as the client becomes progressively more aware of their current approach to situations, sees new possibilities and builds new competences to achieve the desired outcomes. The four stages are (Hunt 2009a: 14-15):
1. Current Way as Subject: not yet visible to the client, the lens through which client sees the coaching topic;

2. Current Way as Object: made visible to the client by offering a metaphor (a symbolic form, e.g. 'A Lone Wolf') by which the client can start to gain distance from it, and see the lens through which the topic was previously seen ('So I am like a Lone Wolf, prowling my grounds, suspicious of everything new ... that is kind of true, isn't it?');

3. New Way as Object: future self that is seen but not yet made subject, for example, a lens that is seen but not yet seen through ('A Leader of the Pack');

4. New Way as Subject / Transcend and Include: by practising new capabilities specifically designed to enhance the appearance and embodiment of the New Way of Being, the client starts to see through the lens of and identify with the New Way of Being ('So in order to really be the Leader of the Pack, I need to sit down with my colleagues and ask how they are doing - each morning for the next few weeks, then jot down afterwards my thoughts about it'). The CWOB never disappears, only the identification with it is made an object, after which it can be operated on and expanded into more expansive ways of thinking and acting.

This means that the NWOB becomes a container for the old, then-Current Way of Being, so as to be able to integrate its strengths ('Lone Wolf has immense capabilities for being alert and detect dangers') and build new competencies ('As Leader of the Pack, I need to be able to approach other "wolves" in a more genuinely interested and open way'). 
INDIVIDUAL ORIENTED COACHING:

Change occurs through insights from inside the client

\section{ACTION ORIENTED COACHING:}

Change occurs through new doings and by accountability

\section{FOUR CHANGE ORIENTATIONS IN COACHING}

CONVERSATIONS ORIENTED COACHING:

Change occurs through conversations and connection
SYSTEMS ORIENTED COACHING: Change occurs through optimizing a person's fit and function in the context of the systems in which they participate

Fig. 5. Common belief structures for change (adapted from Hunt 2009a: 3-18).

Next, we will briefly discuss the coaching process itself.

The processes that different coaching schools use rely heavily on their conceptions of how change occurs. Different schools have different ideas: some engage in conversations only, some in action planning, some in enabling the client to come up with new insights. This can be clarified with the figure above.

Integral Coaching starts with the premise that all of the change orientations are needed. Furthermore, understanding them forms the basis for how they are actually used with a particular client and his unique AQAL Constellation.

Forming a sense of the client's AQAL Constellation is the starting point of an Integral Coaching process. It is a unique view of the client (coachee) seen with set of 'lenses' and woven together to form a sense or a metaphor of how this unique individual experiences his coaching topic. The lenses follow the outlines of the AQAL model, being the quadrants lens, lines of development lens, levels of consciousness (worldview/values) lens, type lens and states of consciousness lens. (Divine 2009b: 41-67)

The Integral Coaching process is composed of four conversations (Hunt 2009b: 69):
1. Intake Coaching Conversation;

2. Offer Coaching Conversation;

3. Cycles of Development Coaching Conversations;

4. Completion Coaching Conversation.

The first conversation occurs as the client brings forth a topic he is interested in exploring. In reality, it is seldom only the wish to explore that initiates a coaching programme. More often than not there is - or at least ideally should be - a genuine yearning to see different results from what one is getting with the current set of thinking and action tools. In the Intake conversation the coach and client get to know each other on a personal, 'lower-left quadrant' level, seeing if there is sufficient mutual resonance to start a professional working relationship. The coach and client form a working definition of the client's coaching topic. Then, as the conversation goes further, the coach asks specific questions informed by the AQAL framework to elucidate the client's Current Way of Being. This CWOB is a combination of the client's AQAL constellation - the lenses through which he sees his topic - and it is the first, and in many ways the most important function of an Integral Coach, to understand this. The understanding deepens in two ways (Divine 2009a: 21-2): 


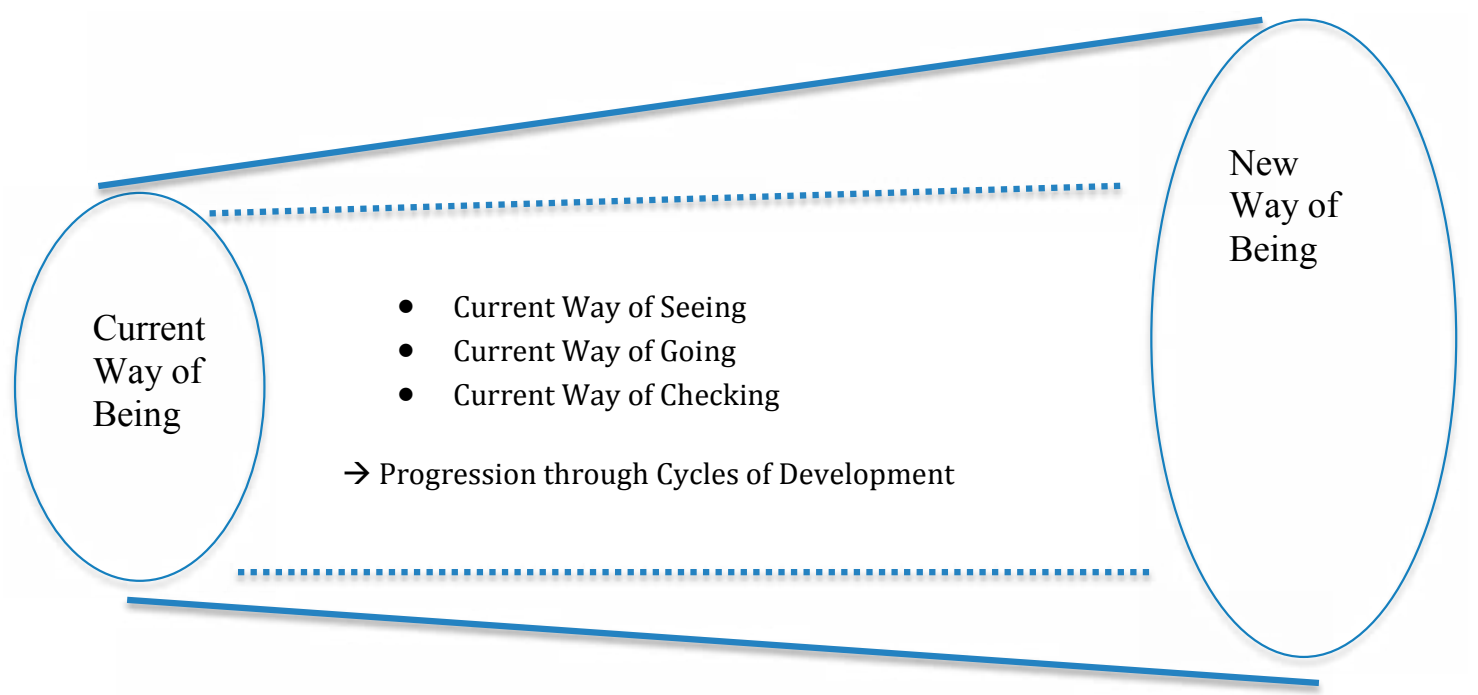

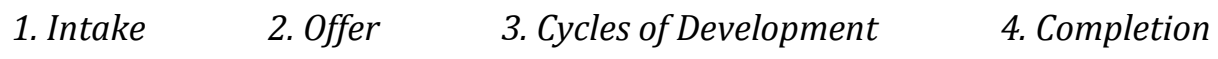

Fig. 6. Process of change through four Integral Coaching Conversations (adapted from Hunt 2009a).

- Looking AT the Client: trying to more fully understand the client by looking at him / her from the outside in (e.g. what are his capabilities in different parts of the AQAL Constellation?)

- Looking AS the Client: trying to understand how the client experiences and looks at the world / topic from the inside out (e.g. how does it feel to be this person?)

This conversation has resemblances to, but is not the same, as is explicated in Andre Marquis' (2008) work on integral psychotherapy.

In the Offer Conversation the coach offers a metaphor for the client that in a symbolic form represents both the Current Way of Being / approaching the topic, and a possible New Way of Being / approaching the topic. Both ways of being are composed of three distinct elements that are necessary for any way of being to stay in motion:

1. Way of Seeing: how we approach, understand and think about the topic;

2. Way of Going: how we take action towards the topic; how we change or try to change what we see;

3. Way of Checking: what measures we check our success/progress against; how do we know we are on the right path.
Offering the metaphor to the client, the coach explains how 1) the CWOB is to be honoured and 2) what it prevents. This is all explicated in relation to the coaching topic. After this, the client usually feels seen by the coach and deeply understood (Hunt 2009b: 77). The main points of this are laid out in the written coaching programme, which is handed out to the client in the Offer Conversation. The Offer Conversation is followed by Cycles of Development conversations, where a new seeing is augmented by a practice in which the client engages in between meetings. Cycles of Development conversations help the client in three ways: 1) to see more clearly their CWOB as object, 2) to see their NWOB as object, slowly transforming into a subject by 3 ) the new doings (practices) and new seeings (reflection) the client explores in between coaching sessions. The sessions themselves can be seen as 'stakes in the ground', while much of the real exploratory work happens when the client and the coach part ways for the 2-3 weeks before the next Cycles of Development Conversation. The final conversation is the Completion Coaching Conversation where the coach and the client reflect on the past developmental journey, assess how strongly the client feels the New Way of Being is felt as a subject, in what ways the (ex-)Current Way of Being is active, and what possible dangers, opportunities and strengths lie ahead. 


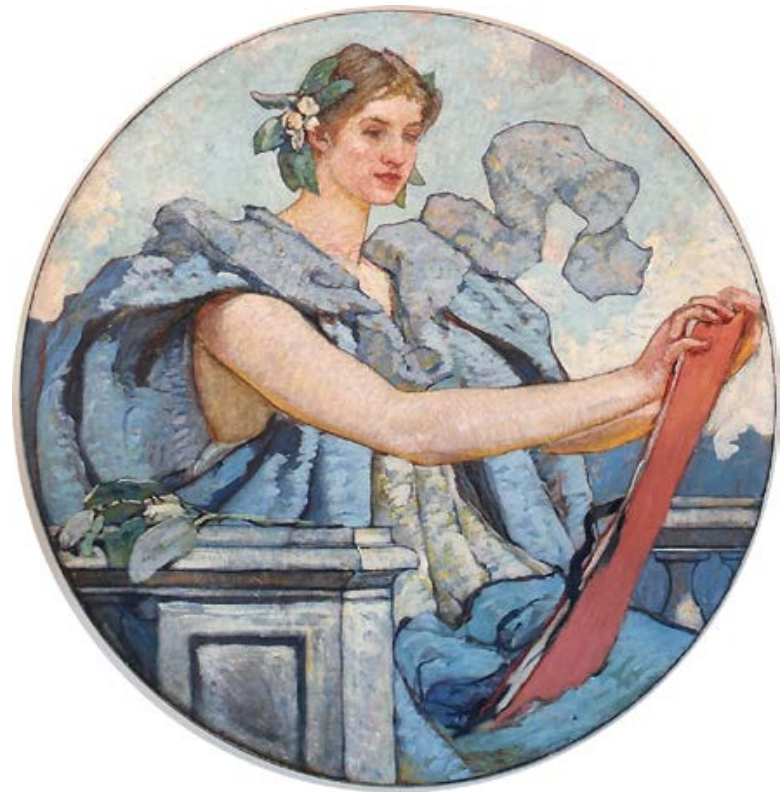

Wisdom, mural by Robert Lewis Reid. Library of Congress Thomas Jefferson Building, Washington, DC. Photo by Carol Highsmith, Wikimedia Commons.

All four orientations of change, as seen in figure 5, are used in the process. There are conversations, new insights and reflections, new doings and practices and accountabilities, and a process guided by a sound method grounded in human adult development theory. The process can be pictured as in fig. 6 .

Through the change process we can see the leaders embodying new levels and ways of being. In order to do this in an organization of a different scale (social holons), we need to foster development on a microlevel (individual holons). The processes are basically the same, as every organization has their own Current Way of Being. It is, however, an unconscionable requirement for an organization to go through a process of change if the leadership is not willing to experience the same process on an individual level. The process of leaders becoming wiser themselves facilitates the creation of a wisdom culture. This happens through a cyclical process of transcending and including what is real today, what is not working, and how we should think and act in order to see ourselves and our organizations from a higher level. It should also be noted that the process of Integral Coaching is only one way to further this endeavour, and we will refine our understanding of how to create wisdom cultures in organizations in the future.

\section{Coaching to see with fresh eyes}

What happens when we are coached to see our situations with fresh eyes? What happens when we approach the same old situations with a new set of perspectives? What happens when our instruments of seeing merge with mental contents that conceptualize the world in a more interconnected, emphatic and multi-dimensional fashion? What happens when we evolve, in a word, our spiritual connection to the world and its constituents?

Here we enter the place where the value of seeing with fresh eyes becomes not a theoretical construct but a practical reality. In approaching situations we can either re-act - to act anew from what we already know - or respond. As noted earlier, the ability to respond requires us to see situations both as if for the first time, giving them the benefit of our un-doubt, and with the widest set of perspectives available.

Creating an internal wisdom culture by first opening up to the possibility that our Current Way of Being (seeing, going, checking) may not be the most skilful way of responding to situations, but rather a conditioned way of reacting from what we already and in a very limited way know, is the quantum leap towards applied foresight in business leadership. It denotes the possibility of an emergent new way of seeing that awaits us should we cast aside the tendency to re-act rather than respond. The conscious growth of the practitioner - here, the leader(s) of an organization - thus relies on our being aware of this ingrained habit. From there we can continue on to the development of seeing with a set of wider and deeper eyes, but only from there. Having a felt sense of actually looking at the instruments of seeing, instead of only looking through them is the first step of overcoming our immunity to change and developing deeper sources of insight, motivation and capability. Usually we tap into those sources only in times of crisis as they arise in a desperate response to an impossible situation; in skilful coaching, however, they evolve organically as a conscious decision to, finally, see the world - our company, our organization, our people - and its issues - stockholder pressure, teams not functioning, ecological concerns, human well-being - with fresh eyes. The wider value of this can be enormous. Having gone through a personal-level change process can take the leader beyond the usual dichotomy of optimism or pessimism, and have a mature, informed optimism come forth from the knowledge that change can and will happen. Seeing with fresh 
eyes gives access to solutions that are only emerging as we are enacting them into being, leading 'from the future as it emerges' (Scharmer 2009). That leading requires courage and a willingness to step into the unknown - and paradoxically, a set of mental contents that conceptualize this unknown in a highly interconnected, systemic and integral fashion. To step boldly into this twin role is the primary function of the twenty-first century leader.

\section{Conclusion: the ontology of wisdom culture}

Ken Wilber's ideas about personal and social growth are based on his ontology of evolutionary systems and in particular on his view of the human being. Humans have, according to Wilber, immense potentialities in terms of cognitive and emotional development. Therefore the notion of wisdom culture, as framed by Richard Slaughter, is not just another fad of consulting business, but a concept that has ontological foundations in the psychological and social development. Spirituality as an implementation of systems thinking amounts to transcending the flatland of one-dimensional materiality, and to reaching new ways of thinking as well as patterns of behaviour. Social growth and better ways of doing business or politics are dependent on individual thoughts and actions, and accordingly the ontology of wisdom culture is dependent on the changes at the upper-left quadrant of individual action. Individuals constitute social systems, and the impact of social systems like corporations is the emergent result of individual actions. It is true that the discipline of comparative religion has not cared so much about making a better world, but the understanding and cultivation of individual and social spirituality, how it transcends the flatland of newness, is an area where comparative religion and business coaching meet and hopefully shake hands.

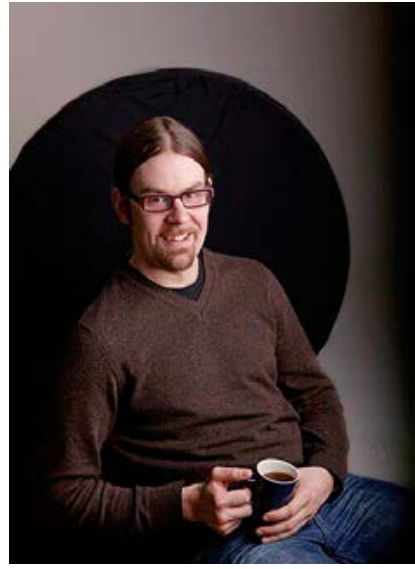

MA, independent scholar JP Jakonen is specialized in the practical applications of Integral Theory in leadership development.

$\mathrm{He}$ is particularly interested in the relationship between the integral model and the good life. Jakonen is a certified Integral Associate Coach $^{\text {TM }}$ and has written three popular books on the Integral Theory as it relates to leadership development and change.

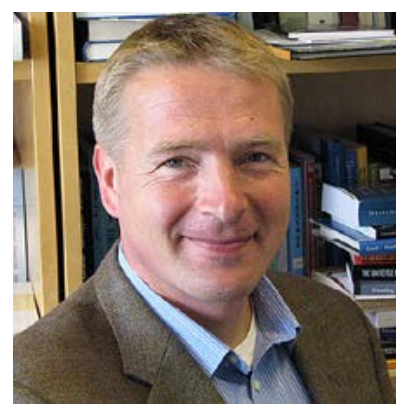

Matti Kamppinen is Professor of Comparative Religion at the Department of History, Cultural Research and Arts Studies at the University of Turku. He has studied Amazonian folk religion, mental models of environmental risks, and philosophical issues in comparative religion. His latest book (together with Pekka

Hakamies) The Theory of Culture of Folklorist Lauri Honko was published by The Edwin Mellen Press in 2013. He has published articles in various journal like Forest Policy and Economics, Method and Theory in the Study of Religion, Technology in Society, Temenos and Futures.

\section{Bibliography}

Bachkirova, Tatiana, Elaine Cox, and David Ashley Clutterbuck, 2010. 'Introduction' in The Complete Handbook of Coaching, eds Tatiana Bachkirova, Elaine Cox and David Ashley Clutterbuck (London, SAGE Publications), pp. 1-20

Beck, Don C., and Christopher Cowan, 1996. Spiral Dynamics: Mastering Values, Leadership and Change (Malden, Blackwell Publishing)

Divine, Laura, 2009a. 'Looking AT and Looking AS the client: the quadrants as a type structure lens', Journal of Integral Theory and Practice, 4(1), pp. 21-40

-2009b. 'A unique view into you: working with a client's AQAL Constellation ${ }^{\mathrm{Ts}}$, Journal of Integral Theory and Practice, 4(1), pp. 41-67

Esbjörn-Hargens, Sean, 2009. 'Executive Editor's note', Journal of Integral Theory and Practice, 4(1), pp. iv-v

Flyod, Josh, Alex Burns, and Jose Ramos, 2008. 'A challenging conversation on Integral Futures: embodied foresight \& trialogues', Journal of Futures Studies, $13(2)$, pp. $69-86$

Frost, Lisa L., 2009. 'Integral perspectives on coaching: an analysis of Integral Coaching Canada across eight 
zones and five methodologies', Journal of Integral

Theory and Practice, 4(1), pp. 93-120

Hunt, Joanne, 2009a. 'Transcending and including our current way of being: an introduction to Integral Coaching, Journal of Integral Theory and Practice, 4(1), $1-20$

-2009b. 'Transformational conversations: the four conversations of Integral Coaching ${ }^{\oplus}$, Journal of Integral Theory and Practice, 4(1), 69-92

Kegan, Robert, 1982. The Evolving Self: Problem and Process in Human Development (Cambridge, Harvard University Press)

-2009. Immunity to Change: How to Overcome it and Unlock the Potential in Yourself and Your Organization (Cambridge, Harvard Business Review Press)

Kofman, Fred, 2006. Conscious Business: How to Build Value through Values (Boulder, Sounds True)

Laloux, Frederic, 2014. Reinventing Organizations: A Guide to Creating Organizations Inspired by the Next Stage in Human Consciousness (Brussels, Nelson Parker)

Marquis, Andre, 2008. The Integral Intake: A Guide to Comprehensive Idiographic Assessment in Integral Psychotherapy (New York, Routledge)

Scharmer, C. Otto, 2009. Theory U: Leading from the Future as It Emerges (San Francisco, Berrett-Koehler)

Slaughter, Richard A., 1998. 'Transcending flatland: implications of Ken Wilber's meta-narrative for Futures Studies', Futures, 3o(6), pp. 519-33

-2004. Futures Beyond Dystopia: Creating Social Foresight (New York, Routledge)

-2012. To See With Fresh Eyes: Integral Futures and the Global Emergency (Indooroopilly, Foresight International)

Stokes, Jon, and Richard Jolly, 2010. 'Executive and Leadership Coaching' in The Complete Handbook of Coaching, (London, SAGE Publications), pp. 245-56

Wilber, Ken, 1996. The Atman Project: A Transpersonal View of Human Development (Wheaton, Quest Books)

-200oa. Integral Psychology: Consciousness, Spirit, Psychology, Therapy (Boston, Shambhala)

-20oob. A Theory of Everything: An Integral Vision for Business, Politics, Science and Spirituality (Boston, Shambhala)

-2001. The Eye of Spirit: An Integral Vision for a World Gone Slightly Mad (Boston, Shambhala)

-2006. Excerpt C: 'The ways we are in this together: intersubjectivity and interobjectivity in the holonic Kosmos', excerpts from Kosmos Trilogy (Boston, Shambhala), <http://www.kenwilber.com/Writings/ PDF/ExcerptC_KOSMOS_2003.pdf > (accessed 3.3.2015) 